\title{
NOTA
}

\section{RIZOBACTÉRIAS FORMADORAS DE ENDÓSPOROS ASSOCIADAS A Tibouchina urvilleana DE ÁREAS IMPACTADAS POR REJEITOS DA MINERAÇÃO DO CARVÃO(1)}

\author{
Bianca de Aguiar Pereira ${ }^{(2)} \&$ Marcus Adonai Castro-Silva ${ }^{(3)}$
}

\begin{abstract}
RESUMO
Os rejeitos da mineração do carvão podem elevar a concentração de metais pesados e dificultar o crescimento de plantas nessas áreas. Uma estratégia para recuperação desses ambientes é por meio da associação de microrganismos à rizosfera que podem auxiliar na promoção de crescimento de plantas, bem como na diminuição da toxicidade por metais pesados. $O$ presente trabalho teve como objetivos o isolamento e a identificação de rizobactérias formadoras de endósporos (RFE) de áreas impactadas por rejeitos da mineração de carvão, num depósito no município de Capivari de Baixo, Santa Catarina (Brasil), bem como a avaliação de seus potenciais para auxiliar plantas na revegetação de ecossistemas degradados por essa atividade, por meio de testes de resistência a elementos metálicos e produção de sideróforos. Das RFE identificadas, as do gênero Bacillus foram mais frequentes, e entre as duas áreas de estudo observaram-se grupos bacterianos distintos. As linhagens provenientes da área dos rejeitos piritosos foram mais resistentes a $\mathrm{Ni}$ e $\mathrm{Cu}$. Dez linhagens pertencentes aos gêneros Bacillus, Paenibacillus e Aneurinibacillus, além de resistirem a um maior número dos metais pesados testados, produziram sideróforos e, portanto, foram consideradas com maior potencial para auxiliar o crescimento de plantas em áreas contaminadas com metais pesados.
\end{abstract}

Termos de indexação: Bacillus, metais pesados, sideróforo.

\footnotetext{
(1) Recebido para publicação em janeiro de 2008 e aprovado em novembro de 2009.

(2) Graduada em Ciências Biológicas com ênfase em Biotecnologia, Universidade do Vale do Itajaí - UNIVALI. Laboratório de Microbiologia Aplicada - Bloco 20 - Sala 127. Rua Uruguai 468, Centro CEP 88302-202 Itajaí (SC). E-mail: biancaaguiarpereira@hotmail.com

(3) Professor do Centro de Ciências Tecnológicas, da Terra e do Mar, UNIVALI. E-mail: marcus.silva@univali.br
} 


\title{
SUMMARY: ENDOSPORE-FORMING RHIZOBACTERIA ASSOCIATED WITH TIBOUCHINA URVILLEANA IN AREAS AFFECTED BY COAL- MINING WASTE
}

\begin{abstract}
Coal mining rejects can raise the concentration of heavy metals and impede the growth of plants in these areas. One strategy for restoring these environments is the association of microorganisms with the rhizosphere, which can help promote plant growth, as well as decreasing the toxicity of heavy metals. The objective of this study was to isolate and identify endospore-forming rhizobacteria (EFR) in areas affected by coal-mining waste, in a deposit in the municipal district of Capivari de Baixo, Santa Catarina (Brazil) and to evaluate the plant growth-promoting potential of bacteria in the revegetation of ecosystems destroyed by mining, based on tests for resistance to metallic elements and siderophore production. Of the EFR identified, those of the genus Bacillus were most frequent, and distinct bacterial groups were observed in the two study areas. The strains from the area of pyrite rejects were most resistant to the metals Ni and $\mathrm{Cu}$. Ten strains of the genus Bacillus, Paenibacillus and Aneurinibacillus, besides resisting a higher number of the heavy metals tested, also produced siderophores and their plant growth-promoting potential in areas contaminated with heavy metals was therefore considered most promising.
\end{abstract}

Index terms: Bacillus, heavy metals, siderophores.

\section{INTRODUÇÃO}

A utilização do carvão como recurso energético gera quantidades significativas de resíduos, cinzas e rejeitos, os quais constituem grande problema ambiental, causando acidificação dos cursos d'água superficiais e de águas subterrâneas, associados à alteração da geomorfologia local. Os níveis de acidificação podem elevar a concentração de metais a níveis tóxicos, prejudicando o crescimento e desenvolvimento da vegetação nessas áreas (Campos et al., 2003). Técnicas como a fitorremediação e a biorremediação são utilizadas com sucesso na descontaminação de metais pesados (Pires et al., 2003).

Das várias relações entre bactérias e plantas, uma das principais contribuintes na absorção e acumulação de metais são as rizobactérias, assim denominadas por colonizarem a rizosfera, camada de solo próxima ao sistema radicular que está diretamente influenciada pela atividade das raízes (Roitman et al., 1987; Melo \& Azevedo, 1998). A espécie Tibouchina urvilleana é pioneira, nativa do Brasil e geralmente encontrada em áreas abertas (Wurdack, 1962); contudo, não há estudos que comprovem o seu potencial como acumuladora de metais pesados, bem como sua aplicação em técnicas de fitorremediação.

Nesse contexto, este trabalho objetivou o isolamento e a identificação de rizobactérias formadoras de endósporos (RFE) associadas a espécimes de Tibouchina urvilleana de áreas impactadas por rejeitos da mineração de carvão, assim como a avaliação de seus potenciais para auxiliar plantas na revegetação de ecossistemas degradados por esta atividade, por meio de testes de resistência a elementos metálicos e produção de proteínas quelantes de $\mathrm{Fe}$, os sideróforos.

\section{MATERIAL E MÉTODOS}

\section{Coleta e tratamento das amostras}

A área de amostragem compreende duas porções de um depósito de resíduos ricos em pirita no município de Capivari de Baixo, em Santa Catarina: uma submetida a um esforço de recuperação, por meio da cobertura e reflorestamento dos resíduos de cinzas; e outra constituída de uma porção dessa área ainda não recuperada. Dois pontos amostrais foram escolhidos, em cada uma das áreas de amostragem, sendo os pontos da área dos rejeitos piritosos situados a $28^{\circ} 25^{\prime} 35$ " de latitude $\mathrm{S}$ e a $48^{\circ} 56$ ' $23,8^{\prime}$ de longitude $\mathrm{W}$, e os pontos da área recuperada, a $28^{\circ} 25^{\prime} 29,6$ " de latitude $\mathrm{S}$ e a $48^{\circ} 56^{\prime} 0,71$ " de longitude W. Foram utilizadas amostras do solo rizosférico de Tibouchina urvilleana, presentes nas áreas de amostragem, coletadas nos dias 1/10/2004 e 28/02/2005. As amostras foram homogeneizadas em solução de $\mathrm{NaCl}$ a $0,85 \%$, por 30 min. A partir da suspensão obtida, foram feitas diluições seriadas, utilizadas nas análises microbiológicas (Hurst et al., 2002).

\section{Análise e identificação das rizobactérias formadoras de endósporos}

Alíquotas das diluições seriadas foram inoculadas em meio Ágar Nutriente (AN) e incubadas por dois dias a $30^{\circ} \mathrm{C}$. A densidade microbiana foi expressa em unidades formadoras de colônias por grama de solo (UFC g-1). As bactérias Gram-positivas e formadoras de endósporos foram identificadas segundo Claus \& Berkeley (1986) e Reva et al. (2001), utilizando critérios morfológicos e bioquímicos. As linhagens Bacillus 
sphaericus 2362, Bacillus subtilis ATCC6051, Bacillus megaterium ATCC14581 e Bacillus thuringiensis isolado no Laboratório de Microbiologia Aplicada (LAMA) foram utilizadas como referências dos testes bioquímicos. A ocorrência das espécies identificadas nas áreas amostradas foi verificada por meio de análise de correspondência.

\section{Determinação da resistência a elementos metálicos e produção de sideróforos}

Treze linhagens selecionadas, crescidas previamente em uma cultura líquida do meio caldo nutriente, foram inoculadas em meio AN. Em seguida, foram colocados discos de papel-filtro, nos quais foram pipetadas as soluções de $\mathrm{CdCl}_{2}\left(1 \mathrm{~mol} \mathrm{~L}^{-1}\right), \mathrm{ZnCl}_{2}$ $\left(1 \mathrm{~mol} \mathrm{~L}^{-1}\right), \mathrm{NiCl}_{2}\left(1 \mathrm{~mol} \mathrm{~L}^{-1}\right), \mathrm{Na}_{2} \mathrm{SeO}_{3}\left(1 \mathrm{~mol} \mathrm{~L}^{-1}\right)$, $\mathrm{K}_{2} \mathrm{Cr}_{2} \mathrm{O}_{7}\left(50 \mathrm{mmol} \mathrm{L}^{-1}\right), \mathrm{CuSO}_{4} * 4 \mathrm{H}_{2} \mathrm{O}\left(1 \mathrm{~mol} \mathrm{~L}^{-1}\right) \mathrm{e}$ $\mathrm{PbCl}_{2}\left(50 \mathrm{mmol} \mathrm{L}^{-1}\right)$, em triplicata. As placas foram incubadas a $30^{\circ} \mathrm{C}$, por $24 \mathrm{~h}$. Por meio das triplicatas, foi tirada a média dos diâmetros dos halos para cada metal de cada linhagem e, posteriormente, determinada uma única média de todas as linhagens testadas, para cada metal. Para analisar os resultados de resistência das linhagens aos metais pesados, foi realizado o teste-T a $5 \%$. As mesmas linhagens foram submetidas ao teste de produção de sideróforos. Para isso, foram inoculadas em placas contendo metade de meio AN e a outra metade de meio Ágar Cromo Azurol S (Schwyn et al., 1987; Milagres et al., 1999). Quando necessário, após a preparação deste meio, adicionou-se ácido clorídrico $\left(5 \mathrm{~mol} \mathrm{~L}^{-1}\right)$ a fim de ajustar a cor para azul. As placas foram incubadas a $30{ }^{\circ} \mathrm{C}$ por duas semanas, e a alteração de cor do meio Ágar Cromo Azurol S indicou a produção de sideróforo pela linhagem.

\section{RESULTADOS E DISCUSSÃO}

\section{Densidade microbiana e frequência de RFE nas áreas e datas amostradas}

As propriedades físico-químicas para cada um dos pontos amostrais e os valores de densidade bacteriana obtidos nos pontos amostrais, nas diferentes datas de coleta, estão representadas no quadro 1 . Na primeira coleta foram isoladas 37 bactérias, sendo 30 bactérias Gram-positivas e formadoras de endósporos (15 linhagens em cada área), as quais foram identificadas. $\mathrm{Na}$ segunda coleta foram isoladas 29 bactérias, das quais apenas 19 eram Gram-positivas e formadoras de endósporos (13 dos rejeitos piritosos e seis da área recuperada). Das 49 RFE identificadas, o gênero Bacillus foi o mais frequente em ambas as coletas, com 27 linhagens. As espécies mais encontradas na primeira coleta foram Bacillus cereus (três linhagens) e Paenibacillus thiaminolyticus (três linhagens). Já na segunda coleta, as espécies mais frequentes nos pontos amostrais foram $B$. cereus e B. silvestris, com quatro linhagens de cada espécie. O gênero Bacillus é um dos mais comumente citados em trabalhos sobre rizobactérias (Freitas \& Vildoso, 2004; Reva et al., 2004; Wang \& Skipper, 2004). Algumas rizobactérias desse gênero também estão incluídas entre as promotoras de crescimento de plantas (Freitas \& Vildoso, 2004). Em áreas impactadas com metais pesados, os endósporos permitem maior chance de sobrevivência à célula bacteriana por serem resistentes a várias condições, inclusive a compostos químicos tóxicos (Madigan et al., 1999).

\section{Ocorrência das RFE nas áreas de amostragem}

Por meio da análise de correspondência (Figura 1) foi possível visualizar grupos de RFE distintos nas duas áreas estudadas, podendo indicar que um local esteja sendo mais impactado com os metais pesados do que o outro, fazendo com que algumas espécies da população impactada sejam substituídas por espécies mais resistentes àquelas condições, alterando a composição microbiana (Rand \& Petrocelli, 1985). Outra hipótese para essa diferença é a distinção paisagística entre os locais; na área recuperada aumenta a presença de espécies vegetais e, consequentemente, de matéria orgânica, aumentando a quantidade de diferentes nichos que podem ser ocupados pelos microrganismos do solo, alterando assim a comunidade microbiana entre os locais (Yin et al., 2000). No entanto, a riqueza de espécies de RFE não foi diferente entre as áreas estudadas, o que

Quadro 1. Valores de densidade de bactérias e propriedades físico-químicas determinadas para os dois locais de coleta, nas duas amostragens realizadas. A densidade de bactérias está expressa em Unidades Formadoras de Colônia por grama de solo (UFC g ${ }^{-1}$ )

\begin{tabular}{|c|c|c|c|c|c|c|c|}
\hline \multirow{2}{*}{ Ponto amostral } & \multirow{2}{*}{ Local } & \multicolumn{3}{|c|}{$1 / 10 / 2004$} & \multicolumn{3}{|c|}{ 28/02/2005 } \\
\hline & & $\mathrm{UFC}^{-1}$ & pH & $\mathrm{T}^{\circ} \mathrm{C}$ & $\mathrm{UFC}^{-1}$ & pH & $\mathrm{T}^{\circ} \mathrm{C}$ \\
\hline 1 & Rejeitos piritosos & 3800000 & 4,30 & 31,5 & 41596 & 3,27 & 37 \\
\hline 2 & Rejeitos piritosos & 2950000 & 4,67 & 31,5 & 330094 & 4,06 & 37 \\
\hline 3 & Área recuperada & 6650000 & 5,34 & 26 & 554907 & 3,86 & 31 \\
\hline 4 & Área recuperada & 2200000 & 4,15 & 26 & 81958 & 3,61 & 31 \\
\hline
\end{tabular}




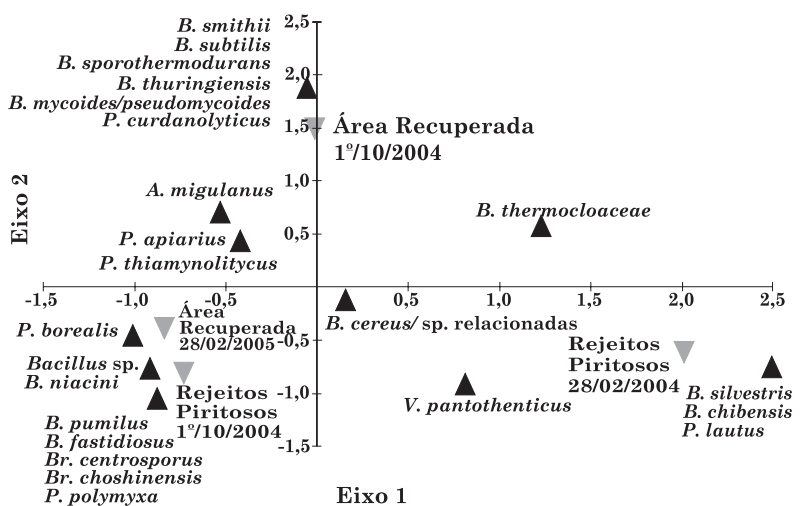

Figura 1. Ocorrência das rizobactérias formadoras de endósporos nos locais e datas de coleta por meio da análise de correspondência.

pode ter sido influenciado pela capacidade que as bactérias possuem de crescer e reproduzir rapidamente, regenerando a densidade populacional original (Rand \& Petrocelli, 1985).

\section{Inibição do crescimento microbiano por} metais pesados e produção de sideróforos

Os resultados obtidos nos testes de resistência a metais pesados demonstraram diferença significativa em relação à resistência das linhagens das áreas amostradas para $\mathrm{Ni}$ e $\mathrm{Cu}$, e os isolados provenientes das amostras dos rejeitos piritosos foram mais resistentes a esses metais. Provavelmente, existe diferença na quantidade ou na concentração de Ni e $\mathrm{Cu}$ nas áreas e, ou, a disponibilidade desses metais para as rizobactérias na área de rejeitos piritosos é maior, fazendo com que estas expressem mecanismos de resistência, tornando-se mais aptas a sobreviverem em tais condições. Além disso, há possibilidade de a flora microbiana estar na forma de esporo, e não ativa, por ser um local impactante.

As linhagens de RFE consideradas com maior potencial para auxiliar as plantas no estádio de revegetação de áreas impactadas foram aquelas que se mostraram resistentes ao maior número de elementos metálicos e que produziram sideróforos (Quadro 2).

$\mathrm{O}$ método utilizado para testar a resistência a elementos metálicos das bactérias deste trabalho permite que isso seja feito com um número maior de linhagens e diferentes concentrações de metais. Foi possível observar que todas as linhagens crescidas na presença de Se resultaram numa coloração avermelhada de suas colônias, consequência da redução do Se em sua forma elementar, um produto

Quadro 2. Linhagens de RFE mais resistentes aos metais (+), menos resistentes (-) e produção de sideróforos. Em negrito, linhagens mais resistentes aos metais testados e que produziram sideróforos

\begin{tabular}{|c|c|c|c|c|c|c|c|c|c|}
\hline \multirow{2}{*}{ Espécie } & \multirow{2}{*}{ Local } & \multicolumn{7}{|c|}{ Resistência a elementos metálicos } & \multirow{2}{*}{$\begin{array}{l}\text { Produção de } \\
\text { sideróforos }\end{array}$} \\
\hline & & Zn & $\mathbf{C d}$ & $\mathrm{Cr}$ & $\mathbf{C u}$ & Se & $\mathrm{Ni}$ & $\mathbf{P b}$ & \\
\hline Paenibacillus thiaminolyticus & Área Recuperada & - & + & + & + & + & + & + & + \\
\hline Virgibacillus panthothenticus & Rejeitos Piritosos & + & - & + & + & + & + & + & - \\
\hline Brevibacillus centrosporus & Rejeitos Piritosos & - & - & + & + & + & + & - & + \\
\hline Paenibacillus apiarius & Rejeitos Piritosos & + & + & + & + & + & + & + & + \\
\hline Paenibacillus thiaminolyticus & Rejeitos Piritosos & + & + & - & + & + & + & + & + \\
\hline Bacillus cereus & Rejeitos Piritosos & + & + & - & + & + & + & + & + \\
\hline Bacillus thermocloaceae & Área Recuperada & + & - & + & - & + & - & - & + \\
\hline Bacillus thermocloaceae & Área Recuperada & + & + & + & - & + & - & - & + \\
\hline Bacillus subtilis & Área Recuperada & - & - & + & - & + & - & - & + \\
\hline Bacillus thuringiensis & Área Recuperada & + & + & + & + & - & - & + & + \\
\hline Paenibacillus apiarius & Área Recuperada & + & + & - & - & + & + & + & + \\
\hline Aneurinibacillus migulanus & Área Recuperada & - & + & - & - & - & - & + & + \\
\hline Bacillus mycoides/pseudomycoides & Área Recuperada & + & + & + & + & + & - & + & + \\
\hline Bacillus niacini & Rejeitos Piritosos & + & + & - & + & + & + & + & + \\
\hline Bacillus cereus & Área Recuperada & + & - & - & - & + & - & + & + \\
\hline Virgibacillus pantothenticus & Rejeitos Piritosos & - & - & + & + & - & + & - & - \\
\hline Bacillus thermocloaceae & Rejeitos Piritosos & - & + & + & - & + & - & - & + \\
\hline Bacillus silvestris & Rejeitos Piritosos & - & + & + & - & + & - & - & + \\
\hline Paenibacillus lautus & Rejeitos Piritosos & + & + & - & + & + & + & - & + \\
\hline Bacillus cereus & Rejeitos Piritosos & + & + & - & + & + & + & + & + \\
\hline Paenibacillus chibensis & Rejeitos Piritosos & + & + & - & + & + & + & + & + \\
\hline Bacillus silvestris & Rejeitos Piritosos & + & + & - & + & + & + & + & + \\
\hline Bacillus cereus & Área Recuperada & - & + & - & + & + & + & + & + \\
\hline Aneurinibacillus migulanus & Área Recuperada & + & + & - & + & + & + & + & + \\
\hline Bacillus niacini & Área Recuperada & + & + & - & + & + & - & + & + \\
\hline Paenibacillus borealis & Área Recuperada & + & + & - & - & + & - & + & - \\
\hline
\end{tabular}


insolúvel e menos tóxico (Kinkle et al., 1994; Garbisu et al., 1995). Outro mecanismo que impede a entrada do metal na célula é a produção de sideróforos, proteínas extracelulares, complexantes de Fe e de outros metais. Produzidos pela maioria das rizobactérias neste experimento, sua função biológica é concentrar Fe em ambientes onde a concentração é baixa e facilitar o transporte para dentro da célula (Maier et al., 2000; Rajkumar et al., 2005). Além disso, podem ajudar as plantas a adquirirem quantidade suficiente de Fe para o crescimento ótimo (Dell’Amico et al., 2005).

\section{CONCLUSÃO}

Dez linhagens de rizobactérias mostraram-se com maior potencial para auxiliar plantas na revegetação de áreas impactadas. Contudo, outros testes de produção de moléculas para melhorar o crescimento vegetal, bem como testes no próprio local contaminado, devem ser feitos para comprovar o potencial observado neste experimento.

\section{LITERATURA CITADA}

CAMPOS, M.L.; ALMEIDA, J.A. \& SOUZA, L.S. Avaliação de três áreas de solo construído após mineração de carvão a céu aberto em Lauro Muller, Santa Catarina. R. Bras. Ci. Solo, 27:1123-1137, 2003.

CLAUS, D. \& BERKELEY, R.C. Genus Bacillus. In: SNEATH, P.H.A.; MAIR, N.S. \& SHARPE, M.E. Bergey's manual of systematic bacteriology. Maryland, Williams \& Wilkins, 1986. v.2. p.1105-1139.

DELL'AMICO, E.; CAVALCA, L. \& ANDREONI, V. Analysis of rhizobacterial communities in perennial Graminaceae from polluted water meadow soil, and screening of metalresistant, potentially plant growth-promoting bacteria. FEMS Microbiol. Ecol., 52:153-162, 2005.

FREITAS, S.S. \& VILDOSO, C.I. Rizobactérias e promoção do crescimento de plantas cítricas. R. Bras. Ci. Solo, 28:987994, 2004.

GARBISU, C.; GONZALEZ, S.; YANG, W.H.; YEE, B.C.; CARLSON, D.L.; YEE, A.; SMITH, N.R.; OTERO, R.; BUCHANAN, B.B. \& LEIGHTON, T. Physiological mechanisms regulating the conversion of selenite to elemental selenium by Bacillus subtilis. Biofactors, 5:29$37,1995$.

HURST, C.J.; CRAWFORD, R.L.; KNUDSEN, G.R.; MC INERNEY, M.J. \& STETZENBACH, L.D. Manual of environmental microbiology. 2.ed. Washington, ASM Press, 2002.
KINKLE, B.K.; SADOWSKY, M.J.; JOHNSTONE, K. \& KOSKINEN, W.C. Tellurium and selenium resistance in rhizobia and its potential use for direct isolation of Rhizobium meliloti from soilt. Appl. Environ. Microbiol., 60:1674-1677, 1994.

MADIGAN, M.T.; MARTINKO, J.M. \& PARKER, J. Brock biología de los microorganismos. 8.ed. Madrid, Prentice Hall, 1999.

MAIER, R.M.; PEPPER, I.L. \& GERBA, C.P. Environmental microbiology. San Diego, Academic Press, 2000. 585p.

MELO, I.S. \& AZEVEDO, J.L. Ecologia microbiana. Jaguariúna, Embrapa- CNPMA, 1998. 488p.

MILAGRES, A.M.F.; MACHUCA, A. \& NAPOLEAO, D. Detection of siderophore production from several fungi and bacteria by modification of chrome azurol S (CAS) agar plate assay. J. Microbiol. Methods, 37:1-6, 1999.

PIRES, F.R.; SOUZA, C.M.; SILVA, A.A.; PROCÓPIO, S.O. \& FERREIRA, L.R. Fitorremediação de solos contaminados com herbicidas. Planta Daninha, 21:335-341, 2003.

RAJKUMAR, M.; NAGENDRAN, R.; LEE, K.J.; LEE, W.H. \& KIM, S.Z. Influence of plant growth promoting bacteria and $\mathrm{Cr}^{6+}$ on the growth of Indian mustard. Chemosphere, 62:741-748, 2005.

RAND, G.M. \& PETROCELLI, S.R. Fundamentals of aquatic toxicology. Bristol, Taylor \& Francis, 1985.

REVA, O.N.; SOROKULOVA, I.B. \& SMIRNOV, V.V. Simplified technique for identification of the aerobic sporeforming bacteria by phenotype. Inter. J. Syst. Evol. Microbiol., 51:1361-1371, 2001.

REVA, O.N.; DIXELIUS, C. \& MEIJER, J. Taxonomic characterization and plant colonizing abilities of some bacteria related to Bacillus amyloliquefaciens and Bacillus subtilis. FEMS Microbiol. Ecol., 48:249-259, 2004.

ROITMAN, I.; TRAVASSOS, L.R. \& AZEVEDO, J.L. Tratado de Microbiologia. São Paulo, Manole, 1987.

SCHWYN, B. \& NEILANDS, J.B. Universal chemical assay for the detection and determination of siderophores. Anal. Biochem., 160:47-56, 1987.

WANG, G. \& SKIPPER, H.D. Identification of denitrifying rhizobacteria from bentgrass and bermudagrass golf greens. J. Appl. Microbiol., 97:827-837, 2004.

WURDACK, J.J. Melastomataceae of Santa Catarina. Sellowia, 14:109-217, 1962.

YIN, B.; CROWLEY, D.; SPAROVEK, G.; MELO, W.J. \& BORNEMAN, J. Bacterial functional redundancy along a soil reclamation gradient. Appl. Environ. Microbiol., 66:4361-4365, 2000. 